\title{
Responsabilidad y esferas de acción
}

\author{
JOSÉ LUIS VILLACAÑAS BERLANGA \\ Universidad de Murcia
}

RESUMEN. En este trabajo desarrollo una ética post-weberiana que asume el principio de la división de las esferas de acción, resultado expreso y central de la modernidad. Sobre este principio, abordo el tema tradicional de la responsabilidad mostrando, primero, su sentido relativo a cada esfera de acción y, segundo, a la administración prudencial de las tensiones que genera la imposibilidad sistemática de integración funcional de las diversas esferas.

\section{1. ¿Tenemos un presente?}

El tiempo que nos ha tocado vivir está sometido a tan tremendas tensiones que estaríamos justificados en lanzar nuestras sospechas sobre quien pretenda alzar la voz con ánimo ufano sobre la responsabilidad. Lo peculiar de nuestra época, en mi opinión, reside en que se ha impuesto con toda desnudez la creencia de que el protoplasma humano es en todo igual que el animal: vida desnuda. En el momento dramático representado por Auschwitz ya se presentía esta verdad, pero no se impuso a las conciencias con claridad. $\mathrm{Al}$ menos entonces, el ser humano requería una calificación para ser sometido a la humilla-
ABSTRACT. I develope in this work a post-weberian ethics that assumes the principle of division of the spheres of action; such principle is the central and explicit result of the Modern Age. On the basis of this principle, I deal with the traditional topic of responsibility and I try to show that its sense is relative, first, to each concrete sphere of action and, second, to the prudential management of the different stresses that provokes the systematic impossibility of a functional integration of such spheres.

ción y al desprecio. Así había judíos y arios, proletarios y burgueses. Hoy no existe necesidad de categoría alguna que ofrezca su coartada a la violencia y la muerte. Más allá de sentimientos momentáneos que hablan de nuestro miedo, parece imponerse la idea de que la muerte es un resultado intrascendente de reacciones químicas, físicas, psíquicas, sociales o políticas. El hombre desnudo ya no esconde tabú alguno y cualquiera, en el sentido más fuerte posible, puede ser el sacrificado. Lo propio de este sacrificio, que contemplamos por doquier en el mundo, es que ya no se legitima en causa trascendente alguna. Con la misma rotundidad que vemos los cuerpos en el fango de los terre- 
motos o los huracanes, los vemos regresar de los campos de la muerte en Colombia, en Nigeria, en las esquinas de los suburbios de Belfast, en las calles de España: una misma naturaleza de las cosas une a las víctimas en la indiferencia pulcra de la agencia de noticias, en los rostros estilizados de los afamados locutores. La evidencia de base es que ningún grito responde a la muerte.

El descubrimiento de esa comunidad universal, definida por la potencialidad homogénea de ser víctima, verdadero contenido de la unidad de la especie humana y de la unidad de la tierra, coincide con el momento en el que la sensación de soledad cósmica pascaliana es más irrebatible. Justo cuando se descubre la comunidad universal del ser hombre como víctima posible, se alcanza el significado apropiado, el valor del imperativo categórico de la dignitas hominis como deber ser. Cuando más necesario nos sería un Dios, más se reduce a un deber ser que habríamos de encarnar nosotros. Hoy sabemos de forma inapelable que este deber, que quizás nos salvaría, está entregado en exclusiva a un ser que siempre puede violarlo y de hecho lo viola. Ya nada nos dice aquella vieja leyenda medieval, que nos refiere Carl Schmitt, y que nos habla del juicio final. En la escena, el condenado lleno de crímenes está delante de la corte de Dios. Y entonces, cuando ha sido sentenciado, sigue en pie y dice «Yo apelo». «Con esta palabra se cegaron las estrellas», nos dice el jurista. Según la idea del juicio final, la sentencia está definitivamente dicha, «effroyablement sans appel». $Y$, sin em-

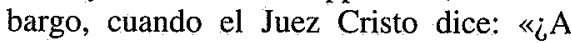
quién apelarás de mi corte?», el condenado contesta en una voz terrible: «Yo apelo de tu justicia a tu gloria.» Hoy no tenemos ese poder, ni esa justicia ni, mucho menos, esta gloria. La causa del hombre sólo puede apelar al hombre: la víctima al criminal. Ese vacío de referencia última deposita en esta palabra, responsabilidad, por su misma grandeza, los tonos dramáticos de la religión. De hecho, al pronunciarla, queremos sustituir estos escenarios de la teología con algo más que una antropología. Inútilmente. Por eso, quien pretenda pronunciar esa palabra con pretensión global, es blanco natural de todas las sospechas.

El mundo global no conoce la responsabilidad clásica. Los analistas que definen el presente como sociedad del riesgo, o los que hablan de la teoría de sistemas, han retirado del mundo elementos que son internos a las evidencias de la responsabilidad. ¿Cuándo han comenzado las consecuencias del empeño humano de quemar todos el combustible fósil de la tierra? Los vendavales y los huracanes que vemos, ¿son hechos naturales? ¿Cuándo acabaron los hechos y empezarán las consecuencias? ¿Quién lo decidirá? Y cuando se presenten, ¿quién será responsable? ¿Quedará alguien para serlo, ante quién serlo? ¿Lo seremos nosotros por no haber prescindido del coche un día antes? ¿Y si nosotros prescindiéramos, seríamos menos responsables por eso? ¿Lo harían los demás? Estas preguntas nos humillan porque nos sugieren con fuerza la conclusión de Luhmann: que ya no hay hombres. Quizás nuestro presente sea algo así como el aplazamiento que nos ofrece un mundo que todavía no se ha preparado para prescindir del hombre. Nuestro único patrimonio es la imaginación, pero sólo para comprobar que somos impotentes para hacer lo posible. El sueño hegeliano de que la especie humana fuera un sujeto, único y penetrante, permitiría adscribirle la responsabilidad por depredar el planeta; pero aunque así fuese, ¿cómo se distribuirían las cargas entre los sujetos de carne y hueso? ¿No sería lo mismo que tener un Dios y un juicio? ¿No es el mismo sueño?

Frente a todo eso, el título de mi exposición tiene una voluntaria humildad. Su deseo es separarse de esa gravedad descrita que, como telón de fondo, acompaña de forma incuestionable nuestra existencia. 
Una vieja estrategia estoica aconsejaba distinguir entre la esfera de acción del logos cósmico y aquella esfera que, hasta cierto punto, tiene el hombre disponible. Sin duda, esta vieja estrategia emergía de una cierta fe, que llevó a Kant a reclamar que viviéramos como si cumplir el deber en nuestra mano tuviera significado respecto a la realidad profunda de las cosas. Esta autorrestricción, propia del viejo estoicismo, intentaba impedir la emergencia de la teodicea, la pregunta por la responsabilidad total del mundo. De esta autorrestricción y de estas estrategias brota el tono menor de mi reflexión. Como he defendido en un artículo que tuvo a bien editar la revista Reflexión de Sevilla, la estrategia apunta al desplazamiento desde la teodicea a ética, cosa que no conviene confundir con la reocupación de la teología por la ética.

\section{Sentido}

Me aproximaré a definir nuestra situación desde las tesis de un pensador que es muy poco conocido en España, pero que ofrece algunos puntos de vista curiosos e intereses. Me estoy refiriendo a Odo Marquard. Uno de sus ensayos, dotados de una agudeza y de un humor muy poco alemanes, porta este título: «Dietética de la expectativa de sentido. Observaciones filosóficas». Como pueden ver, se trata de un pensador bastante excéntrico, pero las cosas que dice son dignas de atención. Pues bien, ese trabajo, que forma parte del libro Apología de lo contingente, comienza con esta tesis rotunda: «El sentido ( $\mathrm{y}$ esta frase es segura) es siempre el sinsentido que uno deja.» Luego, Marquard llama la atención sobre el auge moderno de la experiencia de la carencia de sentido. Por eso, llama al concepto de sentido un concepto patético. En cierto modo, la filosofía se ha especializado en estos conceptos patéticos. Sólo se nombra la palabra senti- do para subrayar el gran déficit que padecemos de él. Así que ante esta experiencia se distribuyen los papeles de la población: por una parte, están los que sepultan el déficit de sentido con la distracción, el dinero, el éxito, el prestigio, el poder técnico, económico o público. Por otra, los que denuncian estos subrogados con furia y señalan que la compulsión y el carácter reiterativo de esa forma de vida denuncia la falta profunda de sentido que padecemos. Marquard ha mostrado que ambas especializaciones, la del filósofo y la del ciudadano de la sociedad de masas, son solidarias. Cuanto más críticamente se propone la necesidad de un sentido en estado puro, y más expectativas de un auténtico sentido se crean, menos se cumplen y más subrogados se necesitan para ocultar esta carencia de cumplimiento. Si expuse mi recuerdo personal sobre aquel investigador, se debe a que en un único caso nos permite mostrar esa solidaridad entre ambos fenómenos. De hecho, nuestro profesor es ambos personajes a la vez, el filósofo riguroso y exigente, que busca un sentido intacto, y el ciudadano de la sociedad de masas; él que en sus libros nos propone exigencias de sentido y de responsabilidad tan extremas que generan expectativas que han de quedar sin responder. Por eso era absurda la censura en aquel caso. Lo que nuestro maestro de la ética padecía estaba más allá de su voluntad y en la síntesis de esos dos aspectos cumplía su sueño máximo: ser hombre representativo de un tiempo que, por doquier, profesa escepticismo respecto a las grandes palabras que misteriosamente no puede borrar.

Así que nuestra dificultad primaria, por hablar con Marquard, está esencialmente en que la filosofía tiene como misión hablar mucho de ciertas cosas para compensar que no existen por ninguna parte. Ella se dedica a los grandes temas con la lente de aumento de la abstracción, de la especialización y así continuamente 
usa las grandes palabras, como son sin duda sentido y responsabilidad. De esta manera intenta ofrecer a la sociedad modelos elaborados y exigentes. Así genera expectativas idealizadas que nadie en la presente situación de masas puede cumplir. Curiosamente, Marquard es más radical que Wittgenstein. Éste recomendaba una dieta variada de ejemplos para no dejarse engañar por la filosofía. Marquard propone, mejor, una dieta de filosofía, para no dejarse engañar por ella.

Espero que se entienda bien a Marquard, o para exonerarlo de toda culpa, que se me entienda bien. No inicio un ataque al gremio de los filósofos. Es un distanciamiento de la función que se tiene asignada la filosofía, la de dedicarse a compensar con intensas repeticiones y quejas sobre la falta de sentido, las evidentes indiferencias que poblaciones inmensas profesan hacia el sentido. De hecho, a la filosofía se le pide poderes mágicos. A fuerza de repetir en abstracto las grandes palabras, se pretende que éstas se encarnen en un mundo que le vuelve las espaldas. Pero la repetición, la mención de las palabras, no generan uso - en el sentido de Wittgenstein - ni significado. La comunicación directa de lo que es responsabilidad y sentido, no genera ni responsabilidad ni sentido. Finalmente, ésta es una técnica casi de exorcista y, aunque grandes filósofos han abusado de ella, ha producido justo el efecto contrario en mucha gente: si un galimatías es el sentido de la existencia auténtica, prefieren quedarse una bonita tarde en el cine.

\section{Responsabilidad: entre la inocencia y la búsqueda compulsiva}

Estoy trabajando con el supuesto de que allí donde Marquard pone sentido, se podía colocar la palabra responsabilidad. Sin embargo, los fenómenos que él registraba a principios de los años ochenta aho- ra están más pronunciados. De la filosofía, lo único que ha pasado a la vida cotidiana son los lamentos acerca de los déficits de sentido y, en cierto modo, también, de los déficits de responsabilidad. Los ciudadanos de todos los niveles y costumbres, de vez en cuando, una vez al día, o varias, se tornan filósofos y deploran las carencias de sentido o de responsabilidad que caracterizan nuestro presente. $\mathrm{Y}$ acto seguido, se entregan a los subrogados del sentido, - consumo, cálculo de bolsa, sexenios de investigación - y como espero mostrar ahora a dos subrogados de la responsabilidad: buscar el culpable y declararse inocentes. Una vez más: nos quejamos filosóficamente de justo lo que hacemos diariamente. Todos somos nuestro famoso maestro de ética en su bien ganada fama de hombre representativo.

Así, en la vida cotidiana, entregada a su lógica interna, se producen estallidos de búsqueda de sentido y de búsqueda de responsabilidad, que tienen asegurada su decepción. En el descanso de nuestro ejercicio preferido, triturar la tierra, devorarla, consumirla, nos preguntamos por el sentido de todo esto y, como en el fondo quisiéramos un mundo que respondiera a las ofertas superexigentes de la filosofía, con un sentido total y una responsabilidad global, caemos decepcionados y nos entregamos con tanta más indiferencia y conciencia de necesidad al consumo. Esta situación es especialmente grave en relación con la responsabilidad. Nadie puede ignorar que nuestra vida cotidiana, anclada en hábitos anónimos y masivos de dudosas consecuencias, queda de vez en cuando atravesada por estériles estallidos de búsqueda compulsiva de responsabilidades, una vez que perdemos la fe en la seguridad que nos da la ciencia y la técnica. Un ejemplo nos llegaba de Inglaterra. Nadie puede afirmar que la forma en que la sociedad actual encara la dimensión sexual del ser humano sea equilibrada, y, sin embargo, ahí está, asumida por todos con naturali- 
dad en la vida cotidiana. Sin embargo, si se publican las fotos de un presunto pederasta, se producen linchamientos como si ese hombre parecido al fotografiado, confuso y sorprendido, fuese el responsable de todos los crímenes sexuales de los que hemos oído hablar. De la misma manera, cuando vemos los icebergs desprenderse del polo norte decimos: que alguien haga algo, que esto va en serio. Olvidamos entonces que sólo hay hombres y olvidamos lo que podemos cada uno de nosotros.

Hago una breve fenomenología de la vida cotidiana. Cuento cómo esa inocencia del consumo es falsa y por eso, de vez en cuando, hay estallidos de angustia. De repente nos damos cuenta de que vamos encima de una ola, vertiginosa, acelerada, y cuando nos bajamos un instante de ella, vienen los estallidos de búsqueda de responsabilidad. En esos momentos preguntamos si hay alguien al frente, alguien que lo controle todo, que lo prevea todo, que nos permita seguir consumiendo con tanta más alegría cuanto más responsablemente él vela por el todo, desde más abajo de las planetas hasta las lentas metamorfosis del carbón fósil. Así, vemos que los fumadores exijan responsabilidades a las tabacaleras por envenenarles; o que los campistas estudien la responsabilidad civil por la torrentera que se llevó a sus familias. Así, nos sentimos desprotegidos y huérfanos cuando una catástrofe destruye una parte de la tierra y, de repente, nos sentimos responsables de ese sufrimiento, saliendo de nuestra angustia con un ingreso en la cuenta corriente apropiada. Es así como transformamos todo el mundo de sucesos en mundo de acontecimientos y acciones humanas, $y$, por tanto, en algo de lo que alguien debería hacerse responsable. Mas como no lo encontramos, volvemos de nuevo al mundo de la necesidad, y el mundo de acciones de repente aparece ante nosotros como un mundo natural de sucesos que nadie puede alterar. Después de muchos siglos interviniendo en la realidad, la dramática situación actual es, justamente, que el hombre ya no sabe poner límites a lo que son sucesos y a lo que son acontecimientos. Al presentir que ese límite es arbitrario, el hombre pasa desde la inocencia que impone una categoría, a la hiperresponsabilidad que impone la otra. Ese paso es compulsivo y obedece a mecanismos de estimulación e hiperestesia que podemos contemplar en nosotros, pero que no podemos controlar.

\section{Responsabilidad y derecho}

Entre este cosmos de inocencia personal y de búsqueda ansiosa de responsabilidades, ambas igualmente falsas y estériles, es lógico que la realidad de la vida social se aferre a algo más sobrio y funcional. La compulsión personal a la inocencia se canaliza a través de la alegría del consumo. El consumo se sustancia en una relación privada con mi dinero. ¿Alguien puede entender, aunque sólo sea por un instante, que en el momento de gastar mi dinero, el dependiente me pidiera cuentas y responsabilidades por gastarlo así, y no de otra manera? Es mi dinero, diríamos. Con él hago lo que quiero. Puedo quemarlo o romperlo. El individuo se sabe alguien mientras tiene dinero y es un individuo solitario mientras pueda gastar. No da cuentas a nadie de sus actos. Consumir, gastar o usar el dinero, es el paraíso de la irresponsabilidad. El dinero es silencioso y sumiso, y por eso permite realizar el sueño de la plena disponibilidad de algo. Los hombres que intervienen en el acto de consumir no actúan con nosotros. Nos sirven. Pueden ser sustituidos por máquinas o por servicios. Nuestra discreción aquí es soberana. Nuestra decisión final es indiscutible. Consumir puede ser, de hecho casi siempre es, un acto privado. Llamo la atención sobre la correlación entre ese acto privado y la carencia de responsabili- 
dad. En estos ambientes, la sensación de inocencia rara vez se quiebra. De hecho, el hombre consumidor obedece al sueño del paraíso.

Cuando esa inocencia se quiebra, sin embargo, se tienen las cosas claras. Una de las manifestaciones de lo que digo es la tendencia, tan irresistible como el consumo, de considerar todas las relaciones sociales bajo el aspecto de la responsabilidad jurídica. Como es obvio, esta universalización de las relaciones jurídicas es resultado de la convergencia de dos fenómenos. Por una parte, la tendencia a que siempre haya un responsable que no sea yo. Por otra, la de que todo responsable genera una indemnización. En el fondo, la sociedad no introduce con ello una forma de relación social diferente de la que ya tenemos como consumidores. De hecho, la indemnización es la compensación por un acto de consumo frustrado y exonera al consumidor de toda responsabilidad. Ésta siempre queda de la otra parte. Universalización de las relaciones de consumo y universalización de las relaciones jurídicas son fenómenos convergentes y satisfacen a nuestras poblaciones porque, al menos en este terreno, siempre es posible satisfacer el ansia de que alguien sea responsable, de que no lo seamos nosotros y de que esa responsabilidad no introduzca una cualidad nueva en nuestro mundo social, porque lo único que se juega en ella es, una vez más, dinero.

Con ello, la noción de responsabilidad se reduce a la de imputación o culpabilidad, el preguntar al reclamar, responder a reparar, y ser sujeto a tener derecho. Estas tendencias, que hacen del tribunal el contexto ante el que se responde, y del código legal el lenguaje con el que se pregunta, son las que alientan una idea ulterior: la de que en ausencia del responsable, el Estado siempre lo es. Si esto ha sucedido es porque así tampoco abandonamos el ámbito de las relaciones económicas. En efecto, el Estado tiene importantes cualidades para cumplir este papel: es el último garante del derecho y de la vida económica, es anónimo, es creado por nosotros y es nuestro protector. El Estado se convierte así en el centro de las desmedidas exigencias de subrogados del sentido y de responsabilidad, pronunciadas por una sociedad que se tensa entre la decepción y el lamento, entre la inocencia y la ansiosa búsqueda de responsables. El Estado, como es obvio, no puede oponerse a estas proyecciones, ante todo porque ha interiorizado la propia relación de consumo y de la vida económica. El ciudadano siempre tiene la razón, como el cliente, porque al fin y al cabo es el cliente. Su voto es el que aumenta o disminuye el capital político del poder y sólo se entrega, como el dinero, con el correspondiente contrato de utilidad marginal. La decepción, el acto fallido de consumo en seguridad y protección, genera la imputación de culpabilidad sobre un empresario político, el partido en el poder, y la promesa de indemnización oportuna por parte del partido de oposición. Nunca se pone en tela de juicio que el ciudadano tiene derecho. Así, el Estado ha de generar fondos para cubrir el paro, $\mathrm{y}$ al mismo tiempo ha de cubrir esos huecos laborales con emigrantes; pero ha de cubrirlos garantizando nuestra percepción de ser inocentes cosmopolitas y las ansias de seguridad y decoro de nuestras ciudades, las exigencias narcisistas de nuestras poblaciones y las exigencias de plusvalías de nuestros empresarios. Cómo haga a la vez todas estas cosas contradictorias, es asunto suyo. Y así, si en la lejana Bosnia se matan dos tribus entre sí, o si en Etiopía y Eritrea dos clanes de señores de la guerra dejan devastada una región entera, los ciudadanos escandalizados se preguntan por qué no hacen algo sus propios Estados. Se supone que ellos son responsables por acción y omisión. El filósofo, en estas situaciones de búsqueda compulsiva de responsabilidad, tiene sus escenarios preferidos porque en los manifiestos a que 
dan lugar funcionan bien las abstracciones de la idealización, la radicalidad teórica, y las reclamaciones llenas de patetismo a favor de un mundo absolutamente humano.

$\mathrm{Y}$ así vivimos. Por mucho que nos sintamos inocentes la mayor parte del día, y por mucho que nos exoneremos de nuestra mala conciencia largando las responsabilidades a los poderosos de la tierra, asentados tras el parapeto del Estado, sabemos que ambas situaciones son igualmente falsas. Quizás por eso nos atenemos al tráfico económico y a la responsabilidad jurídicamente regulada: porque entre tanta inquietud y ansiedad, es lo único palpable y riguroso. Ése es el secreto de su irrefrenable tendencia a monopolizar el sentido de responsabilidad y de la vida: que es funcional y que produce efectos sociales más allá de los sentimientos privados y de las idealizaciones de los filósofos. Por decirlo en términos de la tesis de base a mi argumentación: el mercado se impone por ser el tipo de acción social más simplificado, regulado e institucionalizado; triunfa por disponer del código más explícito y claro y por poseer las instancias especializadas de interpretación y de juicio, de imputación causal - diría Kelsen-y de adscripción de consecuencias. Pero dada su unilateralidad y su mecanicismo, produce las ansiedades y decepciones que hemos descrito. El derecho, la imputación y la pena parece que es todo lo que tenemos: por mucho que lo rechacemos hastiados, siempre volvemos a él.

\section{El carácter indirecto de las realidades humanas}

$\mathrm{Y}$, sin embargo, no podemos resignarnos. La vida social es algo más que la vida jurídica y algo menos que esa responsabilidad global, propia de quien emplea las viejas quejas de la teodicea para dirigirse a los hombres. Parece que entre estos dos ámbitos, los del teólogo y los del jurista, se nos escapa la parte central de nuestra vida. Volvamos entonces al argumento de Marquard sobre el sentido, y veamos si podemos extraer alguna consecuencia ulterior sobre la responsabilidad. Marquard nos propone una salida para aquella paradoja del sentido; a saber: que cuanto más se echa de menos tanto más se pierde. La salida que buscamos, además, debería permitir transformar la función de la institución de la filosofía en nuestras sociedades. Pues bien, la tesis de Marquard procede de Aristóteles y aplica al sentido lo que el Estagirita decía de la felicidad. Todos los hombres aspiran a ella, pero la buscan directamente, como si la felicidad fuese algo concreto, y por eso no la encuentran. Esto de buscar la felicidad de forma directa es una de las supersticiones constantes del género humano. Es como la pretensión de comunicar verdades éticas desde los libros de ética. O como buscar el sentido hablando del sentido. Una superstición paralela podría ser pensar que identificando epistemológicamente la responsabilidad la haremos más presente en el mundo. Cuando pensamos así, somos como aquel paisano de la Enciclopedia de Hegel, que, deseando fruta, rechazó las cerezas, los higos, las peras y los plátanos, porque eran cerezas e higos y demás, pero no fruta. Así, los hombres desprecian el sentido que se le brinda en circunstancias concretas de la vida, sentidos humildes y concretos, porque no es EL sentido de la vida. Pero quien no sea capaz de olvidarse de EL sentido, no tendrá ojos para ver los momentos de sentido que atraviesan nuestra vida.

Como es obvio, y Marquard sabe, esto es propio de los restos de gnosis que atraviesan nuestro mundo y que son mucho más persistentes de lo que Blumenberg ha creído en su magna obra, La legitimidad de la modernidad. Pues la gnosis alienta la promesa de que la experiencia de sentido 
es directa, transformadora, salvadora de este mundo en su totalidad, y al ponernos en contacto absoluto con Dios o con la instancia sagrada de regeneración, nos invita a despreciar todos esos actos cotidianos en los que el sentido brilla en la humildad de lo que es, una planta humana. De la misma manera, el filósofo puede pensar que si define la responsabilidad y la identidad personal, por fín encontró algo capaz de producir un mundo plenamente humano. Esta búsqueda de la responsabilidad global no es menos gnóstica 1.

Una sobria actitud ha crecido a lo largo de la modernidad, sin embargo, desde Lessing o Kant hasta Kierkegaard, Weber y Freud. Esta tradición ha intentado preservar el acceso indirecto al sentido de la vida y la felicidad. Un dicho frecuente entre los rabinos es que de Dios no se habla, se habla con Dios. Podemos decir lo mismo: del sentido no se habla, se habla con él. Igualmente, podríamos decir que se habla desde la responsabilidad, no sobre la responsabilidad. Se tiene acceso al sentido haciendo cosas con sentido, no buscándolo aislado, solo, descarnado. Este centrarse en el sentido de forma directa, nos lleva a despreciar el mundo en la plenitud de sus contextos significativos. Este centrarse en las macrorresponsabilidades totales nos lleva a ignorar nuestro papel como seres responsables. Esta búsqueda de qué sea epistemológicamente la responsabilidad nos impide reconocer los contextos concretos en los que una pregunta puede tener una respuesta. Así que necesitamos un acceso indirecto al sentido y un acceso indirecto a la responsabilidad. Quizás incluso necesitemos una comunicación indirecta en la línea de Kierkegaard para expresar algo que merezca la pena en este campo. ¿Pero qué puede ser esto? ¿Tiene algo en común nuestra búsqueda indirecta a través del sentido, de la felicidad y de la responsabilidad?

\section{Una fenomenología \\ de los bienes de la tierra}

Creo que sí, y espero mostrarlo. La recomendación clásica de un aristotélico consiste en no buscar directamente la felicidad, sino buscar los bienes de la tierra. La recomendación de Marquard era olvidar EL sentido, para gustar los diversos sentidos que genera la vida humana. Lo que hace de nuestro mundo un lugar tan problemático es la creciente reducción de esta pluralidad de bienes, de tal manera que todo se expresa en el denominador común de bien económico protegido por el derecho. Como consecuencia de esta reducción, la responsabilidad se tiende a ver como imputación, culpabilidad, reclamación, reparación. La decisión acerca de la responsabilidad la adscribimos a un técni$c o$, el juez, que sentencia con independencia de nuestra comprensión de la misma. Esa decisión está relacionada con la legalidad, con la justicia legal, el único bien que reconoce el juez. La inocencia, en este mundo, sólo se rompe por un acto de consumo fallido, y se repara con una indemnización correspondiente. La responsabilidad es un estado de excepción de la vida del mercado, de la misma manera que los tribunales lo son del trato social. Al tender al monopolio de la vida social, esta comprensión de las cosas, centrada en la legalidad y el dinero, cubre con un inmenso velo todos los demás bienes de la tierra. Justo porque este único sentido y bien a veces nos asfixia, buscamos EL sentido y EL bien reparador, compensador. La tendencia al monopolio del sentido económico se reproduce en la tendencia al monopolio de la búsqueda de un bien emancipador. Lo constante es la concentración de la mirada en algo Único, salvador de algo único y decepcionante.

Frente a este monoteísmo del sentido, haré una defensa del pluralismo ético. Ahora expondré, de forma muy resumida, una tesis que he desplegado en diferentes 
sitios. Las reconstrucción de la modernidad que hizo la sociología histórica de primeros de siglo, desde Weber hasta Schmitt y Plessner, ofreció una teoría de las esferas de acción social, que reclamó la autonomía de la ciencia, de la vida erótica, de la estética, de la religión, de la moral, de la política y de la economía, como ámbitos fundamentales de la acción social. Ya he mostrado que esta teoría crítica ofrece una convergencia con la teoría del sujeto, sus deseos y sus pulsiones tal y como aprendimos de Freud. Ahora deseo añadir que el contenido de ambas teorías, las de esferas de acción y la del patrimonio pulsional de Freud, pueden exponerse en el lenguaje de una fenomenología que nos ofrece el sentido de los diferentes bienes humanos.

Los bienes de la tierra, en la medida en que anclan en diferentes deseos humanos, no se descubren en la soledad - salvo en las personalidades narcisistas, y entonces tampoco-, sino que se gozan en la acción social de los hombres. Frente a lo que puede parecer, el deseo siempre se canaliza por acciones sociales y se resuelve en sus instituciones. Sólo en ellas se nos ofrecen los bienes que satisfacen la pretensiones de sentido humano. Esos bienes propios de cada una de aquellas esferas de acción social son, correlativamente, la verdad, el amor, la belleza, la bondad, la justicia, la utilidad. Cada uno de estos bienes buscados y realizados en una acción social satisface el deseo de los que intervienen en ella. Cualquier pretensión de satisfacer el deseo que no pase por la acción social, genera personalidades narcisistas. Ellas, más que ningunas otras, viven en la satisfacción que les brinda una imaginación autosuficiente, socialmente apoyada por las instituciones de la publicidad. En otros lugares he mostrado qué patologías conlleva esta forma de relacionarse con el deseo.

En la acción social, el deseo es interpretado, hablado y en ella identificamos lo que resulta desmedido y lo que resulta apropiado. En una palabra: cada bien de la tierra, en la medida en que es tal, es deseado y buscado por los hombres, $\mathrm{y}$, por tanto, puede dar lugar a acciones sociales entre ellos. Aquí profeso un socratismo: no hay forma de conocer uno de estos bienes sin quererlo. La intencionalidad de Husserl no es ajena a la pulsión ni al deseo, y su noción de sentido, desde luego, no incluye sólo contenidos eidéticos, sino también volitivos. Opino, sin embargo, que no hay que buscar una subjetividad trascendental ni una armonía preestablecida de las mónadas racionales capaz de generar intersubjetividad. Lo que mantiene unidos a los hombres, en esa acción social, es la común búsqueda de ese bien, la común identificación de su sentido, la imposibilidad de hacerlo en la soledad sin la drástica reducción a fetiches, la apertura misma de una intencionalidad común que se refuerza en la experiencia compartida y en sus perpetuas metamorfosis. En la medida en que esto sucede, la acción integra un sentido que puede ser descrito fenomenológicamente en sus variaciones concretas. Ese sentido que se abre y se interpreta en la propia acción, con todas sus variaciones y matices, es la fuente del contenido eidético de ese bien, que desde luego se ha interpretado histórica y espacialmente de forma diversa y enriquecedora.

Así que tenemos lo siguiente. La recomendación de Aristóteles dice: no busques la felicidad, sino participa de las acciones con los hombres en la vida de la praxis, y la felicidad, como aceptación del conjunto de la vida, se te dará por añadidura. La recomendación de Marquard diría: no finjas un sentido en tu soledad, idealizando y sublimando tus deseos, buscando EL sentido monoteísta, sino participa de la construcción del sentido apropiado que se verifica en las acciones sociales, sé activo en la interpretación de esa acción. Esta traducción de las recomendaciones de nuestros dos autores puede tener relevancia sobre la manera de escapar a las patolo- 
gías de la responsabilidad, a esta escisión entre la inocencia propia y la búsqueda compulsiva de responsables, superando las reducciones de la vida económica y jurídica y olvidando la responsabilidad total de la teodicea. Aquí la recomendación diría: busca los bienes de la tierra en su pluralidad porque eres responsable de que ellos sigan existiendo, porque sólo en relación con ellos eres responsable, porque sólo desde dentro de ellos puedes ser inocente y culpable a la vez.

Ahora deseo desplegar este argumento. Ante todo, la idea central consiste en ganar el suelo propio de la vida social, en su concreción y su pluralidad. Este suelo es el que buscó la fenomenología en su origen, dejándose llevar por su voluntad de atenerse a las cosas mismas, de penetrar el sentido en su individualidad plena y esencial, y no dejándose engañar por las abstracciones idealizadoras. El camino que siguió cierta fenomenología, lejos del ejemplo husserliano, que se perdió en la investigación trascendental de la subjetivi$\mathrm{dad}$, fue el de atenerse a las acciones sociales como espacio donde brilla ese sentido. Éste es el mérito de la interesante obra teórica de Alfred Schütz y su discípulo, Thomas Luckmann. El resultado de esta línea de pensamiento consistió en que logró proyectar sobre los apuntes weberianos de la acción social el rigor metodológico de la fenomenología. Adaptamos esta línea porque nos permite conducir la mirada a la pluralidad de las esferas de acción social, a la especificidad de sentido finito que se nos dan en cada una de ellas, a las formas del bien que se tejen en las mismas, y a las formas de felicidad que nos ofrecen al conformar, interpretar y colmar deseos y pulsiones. La acción social, así descrita, genera los ámbitos donde la responsabilidad puede querer decir algo concreto. Pues si no conocemos los bienes que orientan nuestra acción social, ni somos conscientes de que sólo en ella podemos disfrutarlos, entonces ien rela- ción con qué vamos a ser responsables? Si no sabemos en qué consisten los bienes de los que hablamos, si seguimos creyendo que la raíz de estos bienes es que nos gustan, si pensamos que cualquier interpretación que demos de ellos es buena porque es nuestra, entonces no sabemos lo que significa ser responsables.

Pondré un ejemplo que espero lo consideren en lo que vale. Al aludir a él no desearía abrir herida alguna. Pero creo que lo que indispuso a muchas personas con el último gobierno socialista español fue la ignorancia de lo que era el bien político por excelencia por parte de ese gobierno. Al no conocerlo no pudieron ser responsables de él. Es más: muchos líderes, que previsiblemente lo identificaron, dieron por sentado que la ciudadanía no lo conocía y pretendieron seguir actuando de una manera contraria e irresponsable para con ese bien. Interpretaron la esfera de acción política y su sentido de la manera más brutal, más primaria, y con ella se dirigieron a la parte social más parcial de nuestro país. Al final, optaron por reducir el bien de la política al bien de la legalidad y ni siquiera cuando fueron sentenciados por un juez pensaron que una sentencia inhabilita para ese bien. Pues tal bien es la representación. Tal bien dice que el representado no puede sufrir merma alguna en su dignidad, que el representado inevitablemente tiene al representante para que, si hay alguna mancha en la res publica, éste cargue con ella y aquél quede intacto en su dignidad. Por eso, el representado no puede ser imputado con el representante, ni puede compartir su lugar en el banquillo, ni puede dar a entender que toleraría de buena gana una sospecha sobre sí al tolerar una sospecha sobre su representante. ¿Qué queda de la ley si el representado carga con su violación? La consecuencia es que al fracturarse ese bien, la propia acción política se quebró para los que conocían ese bien. Obviamente, era imposible que el políti- 
co que no lo conocía respondiera a las demandas de quien lo conocía. De hecho sólo podían responder en el caso de saber de qué se les preguntaba. $Y$ se les preguntaba por qué estaban transformando el vínculo de representación en vínculo de complicidad. Pero ahora esto no es importante: lo mismo podemos decir de los demás bienes. Si no sabemos qué es la belleza, o la bondad, el amor o la verdad, la justicia o la utilidad, ¿cómo responderemos ante alguien que nos pregunte qué queda de todo ello por nuestra forma de llevar la acción social con nosotros?

El mérito inicial de este planteamiento, que habla de acciones sociales donde otros ven sistemas, reside en que nos coloca ante contextos en los que vivimos todos los días. No discuto que las descripciones del funcionamiento social en términos de sistemas y subsistemas no tenga su interés. Discuto que pueda ya arruinar las evidencias de que los hombres actúan socialmente, aunque sea de forma provisional y todo tenga un plazo. No digo que estas actuaciones no estén reguladas institucionalmente muchas veces, pero la regulación institucional es tanto más eficaz cuanto más social es, y menos apela a las líneas de fuerza de la burocracia y sus órdenes jerárquicos. Las instituciones siempre pueden recurrir al paraguas de la autoridad y del derecho, pero entonces tenemos el mundo anterior en que responsabilidad es imputación por parte del que puede imputar. La clave de estos contextos jurídicos es que la asunción de responsabilidades depende de la imputación por parte de una decisión externa. El mérito de la estrategia que invoca la acción social reside en que nos coloca ante contextos concretos en los que tiene sentido la pregunta y la respuesta porque no entrega a especialista alguno ajeno a los actores el juicio sobre el bien en cuestión. El juicio aquí forma parte de la acción. Hace que esquivemos preguntas sobre responsabilidad global, para que nos centremos en la acción de responder, sus contextos, sus sentidos y sus formas. Genera así una forma de responsabilidad que es interna a la propia acción social, que no requiere instancia externa de imputación, ni sentencia neutral, ni pena, ni corrección; pues la imputación es adscripción libre, la sentencia es reconocimiento, la pena el dolor por no poder disfrutar de un bien humano y la corrección el perdón.

Tenemos así dos fenomenologías: la responsabilidad como derecho o como acción social. Como es lógico, preguntar y responder en este último caso sólo tiene sentido desde el conocimiento de la lógica de cada esfera de acción social, desde el sentido y el bien propio que nos jugamos en cada una de ellas, desde ese código jamás formalizado, resultado de su propia praxis. En estos contextos, preguntar por la responsabilidad sólo tiene sentido desde la lógica del participante en la acción social y es una de sus competencias. Es una pregunta práctica, no teórica, y tiende a seguir permitiendo la acción social. Si amamos el mundo porque encontramos sentidos en nuestras acciones, la pregunta por la responsabilidad está ante todo dictada por la vocación de seguir amando el mundo y, por eso, se supone que es común al que pregunta y al que responde. Preguntar y responder es un compromiso contra el gran enemigo, la desesperación, que nos deja en la soledad y nos abre la puerta al narcisismo.

Además, la pregunta por la responsabilidad en cada una de estas esferas no puede abordarse desde los esquemas de funcionamiento de otra. No podemos alcanzar competencia para comprender y preguntar si alter ha sido responsable respecto a la verdad de su trabajo científico de la misma manera que aprendemos a preguntar si ha sido responsable respecto al amor que, según dice, nos profesa. Responsabilidad supone así un sentido para la pluralidad de los bienes humanos y sus formas específicas de mantenerse en la acción. Así, nos vacunamos contra la inclinación hacia la 
monopolización del sentido de nuestra vida por una esfera única, sea la esfera económica o cualquiera otra. Al atenernos a esta exigencia de concreción y de pluralidad, se arruina todo intento de idealización, monopolización o radicalización del sentido. Por lo demás, si se aceptan estas premisas, la filosofía no es una reflexión sobre las grandes palabras, responsabilidad, sentido, felicidad, en intención directa, sino sobre los diferentes bienes, sentidos y deseos en los que se genera las diferentes acciones sociales, las diferentes formas de preguntar y responder, las diferentes estrategias de velar por esos bienes y no destruirlos. La filosofía es la heredera de las ontologías regionales, de los reinos del ser, de las fenomenologías particulares. Incluso estoy por decir, platónicamente, que la filosofía es la memoria de las acciones sociales en las que descubrimos esos bienes, el intento de captar eidéticamente en su forma originaria su sentido. De esta forma, la filosofía escapa a su misión otorgada de compensación teóricaradical ante una vida social desvalida, de representar las grandes palabras con mayúsculas, para remangarse en la harina de la acción social, como competencia concreta de interpretación, de recreación, de renovación del sentido, de aceptación de los bienes concretos de la tierra y de expresión del amor al mundo que su disfrute y preservación provoca. La filosofía no es un metarrelato o un metadeber sobre el mundo como totalidad -actitud ya despreciada por Kant-, sino un plus de conciencia en la forma de desplegar las diferentes esferas de acción social, de comprender sus sentidos y sus bienes, de entender su relevancia para la felicidad. Filosofía es otra palabra para responsabilidad y no tiene otro fin que recordarnos que hemos de mantener el brillo de los bienes humanos. Así estaremos en condiciones de asumir el resultado más poderoso del proceso moderno, la agudeza de mirada para no dejarnos engañar por nin- gún falso monoteísmo de valor, por ningún reduccionismo ni dogmatismo.

\section{Esferas de acción y sus condiciones}

Ahora argumentaré en favor de lo dicho desde otra dirección, que me llevará al tema de los derechos. Lo propio de una esfera de acción social es que supone la participación de sujetos que llamamos modernos. Nos representamos tales sujetos dotados de la competencia hermenéutica y capaces de asumir las ideas de libertad e igualdad para hablar, preguntar y responder. La acción social no define una estructura de coacción, ni está reglada por la legitimidad tradicional. Es una estructura reversible de pertenencia, no una irreversible y ontológica. Supone que los sujetos asumen el bien que buscan por su valor de bien, no por ser subrogado de otro bien. Supone entonces la franqueza y la sinceridad expresiva de los participantes, pero también que este bien que se busca es comprendido, y aunque tenga diversas interpretaciones, sólo puede ser exitosa la acción social cuando al menos se acuerda una interpretación tal que los sujetos participantes sientan su deseo satisfecho por esa interpretación.

En este contexto vemos con claridad que la responsabilidad, la capacidad de hacer preguntas y respuestas, no es nada ajeno a la acción social, sino su estructura misma, su condición interna de posibilidad y de éxito. No se puede ser responsable si no se ha definido o asumido la interpretación del bien que persigue esa acción social y respecto de la cual serán valoradas nuestras acciones. Es más: inicialmente se es responsable en relación con ese bien, no en relación con cualquier otro. Obviamente, se puede ser responsable de las consecuencias que para otro bien tiene buscar uno dado. Así, buscar la ciencia o la riqueza puede arruinar la familia o el sentido de la belleza o la religión. Pero 
entonces tenemos que entrar en la esfera de acción pertinente a ese bien, reinterpretarlo junto con los demás actores de esa esfera, dar y ofrecer respuestas y explicitar nuestras jerarquías entre los bienes, comprometernos con las renuncias concretas a que estemos dispuestos y la forma en que eso puede afectar a las expectativas de nuestros alter. Cuando más explícitos seamos, no sólo en las consecuencias internas, sino en los ajustes en relación con las otras esferas de acción, tanto más responsables seremos, desde luego. Con ello vemos que esa conciencia que produce la filosofía siempre nos trae la noticia de heridas, porque no hay forma de ser responsable con un bien sin renunciar al disfrute de otros.

Estoy dando razones en relación con algo que juzgo importante. Los filósofos han buscado el vínculo de la responsabilidad como semejante al de imputación. Han querido hacer de la responsabilidad un asunto teórico y propio del conocimiento. Tengo para mí que la responsabilidad emerge de la interpretación de la acción social y la adscripción de responsabilidad forma parte de esta misma interpretación. La responsabilidad es un vínculo hermenéutico, no causal. Por eso está llena de ambigüedades y dolores y por eso necesita de la libertad para zanjarlas, aceptarlas, asumirlos o perdonarlos. En la medida en que analiza el curso de los sucesos fruto de la acción, comparando hechos y consecuencias con el sentido del bien propio de esa esfera, está uniendo dos dimensiones heterogéneas - hechos y sentido - que sólo pueden reunirse por la libertad y la interpretación. Pero la libertad no acepta las consecuencias, los sucesos, el curso de las cosas, de una manera física, como si fuera naturaleza: los acepta en tanto que acontecimientos ya interpretados y humanizados. En tanto que tal, no hay fuerza humana ni divina que pueda imponer la responsabilidad o que pueda retirarla. Desde luego, nadie puede obligar a responder ni siquiera ante el tribunal oportuno y de forma incondicional, sino en la medida en que el tribunal sea reconocido como legítimo por el juzgado. Cuando a Carl Schmitt le preguntó el jurista Kaulbach, en el proceso de Nuremberg, « ¿Es usted Carl Schmitt?», el jurista del Reich, que conocía a su interlocutor porque había vivido en el mismo patio en Berlín, contesto: « $_{i} Y$ quién es usted para preguntarlo?» Ni siquiera el tribunal puede imponer responsabilidad, como hemos visto con demasiada frecuencia en nuestros días. La responsabilidad sólo puede asumirse desde dentro de la acción social, y sólo será aceptada y asumida por el que aparece responsable si está dispuesto a seguir la acción social de alguna manera y mantenerse fiel a ese bien. En este sentido, la interpretación de responsabilidad es condición de continuidad de la acción y sólo bajo este supuesto se hace evidente. Ahora bien, como cualquier acción social está endémicamente amenazada de quiebra, en cualquier momento puede emerger la libertad formal para desvincularse de la responsabilidad y sus interpretaciones, Lo que queda entonces es una quiebra y un silencio, la soledad y un dolor irreparable, que será tanto más intenso para aquel que ha hecho de la acción social el lugar en el que disfrutar de los bienes del mundo. Una de las cosas que debemos saber, sin embargo, es que hablamos de bienes humanos, y que no hay manera cierta de guardar silencio ante los hombres con los que compartimos ese bien y pretender seguir disfrutando del mismo. Sabemos to suficiente como para creer que el rechazo de la responsabilidad nos resulte gratis y quede impune. Esto sucede si juzgamos en términos de la fenomenología del derecho. Las heridas a los hombres aquí son heridas a los bienes mismos. Por eso hemos de suponer que, en la medida en que disfrutemos de ellos, estaremos dispuestos a preservarlos y, en esta misma medida, estaremos dispuestos a asumir nuestra res- 
ponsabilidad y responder realmente de nuestra acción. Pero como no es posible atender todas las esferas de valor, todos los bienes humanos a la vez, no podemos evitar la herida y la tragedia de reducir nuestro consuelo, de cargar con una felicidad cada vez más problemática y cada vez más ambigua.

\section{Conclusión: Responsabilidad $y$ derechos humanos}

Se podría extraer del mundo de la literatura y del arte muchos ejemplos sobre la responsabilidad y sus contextos. En la literatura se ha ejercido una fenomenología de la vida con mucha más nitidez que en la filosofía, desde luego. Ninguno de estos ejemplos nos enseñarán qué es la responsabilidad, pero nos hacen más competentes para hacer esas preguntas, a nosotros y a los actores, y nos enseñan a reconocer las respuestas que nos permiten mantener o romper la acción social, reconocer la culpa y asumir un saber práctico para seguir tras los bienes irrenunciables. Esta enseñanza puede exponerse humildemente. Sólo porque la acción social está bien trabada, se puede exigir la responsabilidad y ésta puede quedar adscrita de forma tan verdadera como la luz del sol. Sólo entonces puede ser asumida o no, sólo así puede producir silencio o una segunda oportunidad. La responsabilidad es la propia estructura de una acción social autoconsciente. Con ello nos damos cuenta de que la condición para que la responsabilidad sea demandada y se adscriba, es sencillamente que la acción social esté bien construida, que genere su contexto claro, que los sujetos sean iguales y francos en la persecución de ese bien, en su capacidad de interpretar y valorar las consecuencias y juzgar si cumplen o no los bienes buscados. Sólo tras haber impuesto estas garantías definitorias de la acción social, se está en condiciones de dar razones aplastantes que hacen callar al otro cuando se le adscriben las consecuencias nefastas que se han seguido de la acción y que la rompen. Sin acción social bien planteada no hay responsabilidad. Y por eso, nuestra única meta-responsabilidad, el único contenido de la filosofía en este sentido, dice que hay que entrar sólo en aquellas acciones sociales que tengan bien definidas las garantías que permiten identificar responsabilidades, esto es: sujetos que interpreten de forma común el bien que buscamos, que sean competentes en él, que tengan experiencia del mismo, que logren hacer bien las preguntas y no acepten la primera respuesta como válida.

Ahora bien, esto significa una cosa esencial: que sólo los que son expertos en actuar socialmente en las diferentes esferas están en condiciones de llevar adelante argumentos para identificar la responsabilidad en ellas. Las cautelas para interpretar el bien buscado, las competencias para apreciar las consecuencias nos deseadas, las retóricas para exigir explicaciones y para adscribir autorías, en la medida en que siempre se dan en contextos concretos, requieren experiencia, no teoría. Dar el paso de la libertad que dice «yo lo he hecho» requiere sobre todo autoconciencia, pero también una exhortación permanente a darlo desde la disponibilidad al perdón. Responsabilidad es una práctica justo porque depende de una hermenéutica de la que no está excluida la intención.

La descripción de casos ideales, de casos esenciales, es la única fuente de la que tal conocimiento puede brotar. Tal cosa es, o debería ser, la educación. Sin competencias experienciales, no existe posibilidad de identificar responsabilidades, ni de tomar decisiones acerca de si la acción social puede seguir o no. De ahí que, excepto en los sujetos religiosos, que están en condiciones de asumir toda la responsabilidad por el mal del mundo, de tal manera que importe más identificar el mal que quién sea su autor, excepto en estos 
casos en que los hombres sufren por el dolor del mundo, el mundo seguirá sin definir responsabilidades salvo en la medida en que los que intervienen en la acción social no posean la igualdad material en competencia hermenéutica y la libertad y sinceridad en la que se funda la condición moderna.

La responsabilidad o emerge de la acción social bien planteada, o no emergerá jamás. Para eso se requiere competencias experimentales de las diferentes esferas de acción social en las que se dan los bienes de la tierra. La vieja teoría de la justicia, magistralmente reformulada por Michel Walzer, se concentra en la distribución plural de los bienes. Ahora vemos que se abre aquí una teoría de la justicia que entrega argumentos a favor de la no exclusión de la acción social. En esta teoría de la no exclusión ancla para mí hoy el pensamiento político. Sin esa justicia distributiva del saber práctico ganado en la experiencia de la acción social no hay responsabilidad ni disfrute de bienes. En el fondo, esta teoría va más allá de la tesis clásica y ofrece un contenido a la distribución de la igualdad, la libertad y la autonomía humana. Sin duda, éstos son derechos humanos como garantía formal de que los hombres puedan acceder a estos bienes materiales. Mas éstos sólo se dan en la acción social verdadera que pone en acto aquellos derechos fundamentales. Lo que todo derecho fundamental promete realmente al hombre es la participación en los bienes de la tierra. Ya hemos visto que sólo los no excluidos de estas esferas de acción tendrán acceso efectivo a estos bienes. Pues ya hemos visto que no ser excluido de la praxis es condición para ganar competencias hermenéuticas a la hora de plantear de forma autoconsciente la acción social y así tener posibilidad de exigir y dar responsabilidades. Al fin y al cabo, dijimos que exigimos responsabilidad para mantener y prolongar la esfera de acción. El derecho de no exclusión es lo único que puede permitir todo eso. El derecho de pedir y dar respuestas está en juego como último derecho en el que se concentra una vida social ordenada. Sólo sin exclusión puede conseguirse y sólo así puede abrirse camino una vida alejada de la inclinación a la inocencia y alejado de la inclinación a la seguridad. Que la acción social, una planta frágil, con sus bienes y afectos, se rompa, depende de nuestra capacidad de preguntar y de responder. Pero también de nuestra valoración de esos bienes. Para ello se requiere un saber experiencial del participante. He hablado de los bienes de la tierra. Y he alegado en favor de un verdadero reconocimiento de su pluralidad, ahora en peligro desde el reduccionismo económico y jurídico. Ahora vemos que el único bien de la tierra, el trascendental, reside en gustar del trato con los hombres. Todo lo que deseamos, lo conseguimos por el rodeo que damos entre los hombres. Hemos visto que esto no es posible sin dolor y sin heridas. Sólo esa evidencia nos dispone a obtener también la más difícil de las competencias, la del perdón. Ahora ya sabemos dónde reside la dificultad de la responsabilidad y su dimensión utópica. Pero al menos, cuando la filosofía brotaba de la vida, ésa fue su evidencia. La no exclusión de la acción social es el derecho humano por excelencia, pues esa exclusión lleva consigo la de la condición humana. Ése es el único camino para no quedar excluido de este conocimiento de claroscuros y de inquietudes que da respuesta y la pide, con todas las ambigüedades y con todo el proceso de interpretación perenne, de goce, libertad y perdón que es la verdadera existencia humana. 


\section{NOTAS}

1 Como diría Weber, éste es el origen del misticismo acósmico, que rompe los ámbitos concretos de la vida como si fueran despreciables, y lo hacen depender todo de las potencias carismáticas que irrumpen de forma revolucionaria y que ponen al hombre ante la experiencia directa del sentido. Pues, como dice S. Pablo, ahora miramos como por un espejo, pero cuando ÉL se nos da, miraremos cara a cara.

De naturaleza igualmente gnóstica son esas subjetividades omnipotentes para el bien o para el mal, para la conspiración universal y para la protección universal. Los que ya vamos dejando de ser jóvenes podemos recordar cómo ambas actitudes se daban en las mismas personas de manera radicalmente sintética hace unos años, tan sólo. Muchos de nuestros amigos podían pensar que la potencia conspiradora universal, los Estados Unidos, necesitaban una potencia benévola y salvadora igualmente universal, que estaba alojada en el Kremlin. Para otros era justamente a la inversa. Allí, en ellos, estaba la responsabilidad en estado puro. Nosotros, no éramos sino herramientas de cada una de estas subjetividades omnipotentes y salvadoras en lucha. Entonces existía un mundo en el que las grandes ilusiones de los hombres, la inocencia, la protección y la responsabilidad global, tenían referentes. Sin duda, estas ilusiones eran su máximo sostén. 